\title{
ÉTICA E POLÍTICA EM DON JUAN MANUEL
}

Maria Guadalupe Pedrero-Sánchez"

SINTESE - Don Juan Manuel foi uma das personagens de maior relevo no século XIV em Castela, tanto pela sua obra literária quanto pela sua participação ativa na politica da época. Era nobre, guerreiro e ao mesmo tempo tinha uma consciência clara de escritor. Preocupa-se por conciliar o que pensa e propõe (ética), e o que vive intensamente (política). Detectar as linhas mestras e os conceitos presentes no pensamento do autor assim como a projeção dessas idéias na sua prática política, é o objetivo do presente trabalho.
ABSTRACT - Don Juan Manuel was one of the most relevant characters in the 14th century in Castela (Spain), as much by his literary works as by his active participation in the politics of his age. He was a nobleman, warrior and at the same time had a clear awareness of a writer. He worried at the conciliation of his thoughts and proposals (ethics) and what he lived so intensively (politics). To trace the main lines and the concepts that are found in the thought of the author and the projections of these ideas in his political practice, is the purpose of this article.

Ao tratar do tema "Ética e Política na Idàde Média", a figura de Don Juan Manuel apresenta-se como paradigma de um valor excepcional, pois oferece, através da sua vida, uma visão completa do panorama político e social do seu tempo. Não é considerado nem se considera pessoalmente um "filósofo"; porém, nos seus tratados, sem a pretensão de uma análise sistemática, oferece o exemplo de uma atividade política efetiva, o qual justifica a sua inclusão neste Congresso.

Herdeiro de Alfonso X, o Sábio, uma das figuras mais representativas do saber enciclopédico caraterístico da "intelectualidade" medieval, alimenta-se, como ele, de uma fonte comum, inserida no âmbito da tradição ocidental, continuadora da antigüidade clássica e em sintonia com as correntes de pensamento da época . Dessa tradição recebe as suas idéias sociais e religiosas, a técnica escolástica da sua exposição doutrinal e a sua orientação de escritor didático.

Por outro lado, Don Juan Manuel aparece como figura controvertida, se queremos abranger conjuntamente imagens tão opostas como são a sua vida pública, marcada pelo orgulho e sagacidade política orientados para o acréscimo do seu poder, e a do homem de letras, em cuja atividade literária se descobrem, também, as tendências antagônicas próprias da Baixa Idade Média : busca de clareza e aproximação do leitor e, ao mesmo tempo, desejo de obscuridade retórica, própria de iniciados; apego ao saber tradicional do livro e simultaneamente orgullho e auto-afir-

* Universidade Estadual Paulista - UNESP - Assis, SP

\begin{tabular}{|l|l|l|l|l|l|}
\hline VERITAS & Porto Alegre & v. 40 & $\mathrm{n}^{2} 159$ & Setembro 1995 & p. 659-666 \\
\hline
\end{tabular}


mação de uma experiência pessoal; humildade do artista enquanto simples instrumento divino e ao mesmo tempo consciência do seu próprio valor.

O que predomina na sua produção literária, porém, é uma forte individualidade, o desejo expresso de transmitir a sua experiência e, nesse sentido, perpetua nas suas obras a busca de justificativas racionais para o seu gênero de vida. Era nobre e guerreiro e estava ao mesmo tempo intimamente relacionado com a ordem dominicana. Preocupa-se em conciliar ambas as coisas, o que pensa e propõe ética - e o que vive intensamente - política.

Cioso sempre e consciente do legado das suas obras, é através do próprio autor que conhecemos a sua produção literária, à qual faz referência com autocitações enumerando os seus livros no prólogo de $O$ Conde Lucanor, remetendo às fontes autênticas corrigidas, revisadas e depositadas por ele mesmo no convento dominicano que ele constrói, protege e patrocina junto ao seu castelo de Peñafiel.

Duas obras merecem especialmente a nossa atenção: O Livro dos Estados, como síntese do pensamento doutrinal do autor; e $O$ Conde Lucanor ou Livro de Patrônio, como síntese de uma conduta a seguir na realidade concreta do dia-adia, apresentada através de uma série de exemplos, cuja narrativa retrata atitudes mais do que personagens, como fruto da experiência e do mais puro pragmatismo.

\section{O Livro dos Estados!}

A tese central da obra O Livro dos Estados pode ser assim resumida: o fim último do homem é a salvação da alma. Tal salvação consegue-se pelo cumprimento de determinados deveres de ordem social, correspondentes ao próprio estado. Pode ser considerado, também, como uma glorificação do homem no mundo, um microcosmo, no qual se adaptam forma e conteúdo. O movimento ascendente que carateriza o livro está inspirado em Santo Tomás e significa a ascensão gradual do homem para o seu destino, elevando-se, aperfeiçoando-se e despojando-se pouco a pouco da imperfeição e do pecado. ${ }^{2}$

A obra está dividida em três partes. A primeira dedica-se às diferentes leis religiões - e trata do estado dos leigos. A segunda trata das diferentes leis e do estado dos clérigos seculares. E, por fim, a terceira dedica-se às ordens religiosas.

Será ainda o próprio autor quem indica a técnica literária utilizada ao apresentar o livro, em forma de perguntas e respostas que faziam entre si um rei (Moroban), um infante seu filho (Johas), um cavaleiro preceptor do infante (Turin) e um filósofo (Julio). ${ }^{3}$

A inspiração tomista manifesta-se nitidamente na terceira parte, constituída pelo capítulo 51, no qual, ao tratar das ordens religiosas, concentra a sua atenção na ordem dominicana para descobrir nas suas constituições os alicerces sobre os quais justificar o próprio estado e ainda o seu pensamento político.

1 O termo estado em Don Juan Manuel, tanto no que se refere ao título como ao significado posterior do termo, é equivalente a estamento.

2 GIMENO CASALDUERO, J. "El Libro de los Estados de don Juan Manuel: composición y significado". In Don Juan Manuel. VII Centenario. Murcia, 1982, p. 149 - 161.

3 Libro de los Estados. Publica: GOYANGOS, P. Escritores españoles anteriores al siglo V. BAE, V. 51. Madrid, 1952, p. 365. As citações de Don Juan Manuel corresponderão a esta obra. 
A conveniếncia de manter a pluralidade de ofícios, estados e hierarquias, para que reine a paz espiritual e social dos homens, ${ }^{4}$ é princípio recolhido e aceito por Don Juan Manuel como útil e adequado para a salvação do indivíduo. Lembra ainda que Santo Tomás define estado em relação com liberdade e servidão. E recolhe a fórmula com a qual professam os dominicanos: "queremos que as nossas constituições não nos obriguem à culpa senão à pena", idéia sobre a qual monta a sua argumentação, pois os religiosos comprometem-se a viver segundo a regra e não a submeter-se a todos os seus pormenores. ${ }^{5}$

É pois o uso prudente de um estado e a aceitação prudente - cautius - de umas obrigações o que faz caminho de perfeição para esse estado ou essas obrigações.

A última parte do livro converte-se assim numa exaltação da sensatez, enquanto capacidade de escolher como forma de existência, não precisamente 0 meio de salvação mais seguro, mas aquele que, sendo mais perigoso, permite conciliar os bens temporais com os bens eternos.

Sempre na esteira de Santo Tomás, defende a combinação do ativo e do comtemplativo, combinação esta que pode aconselhar, também, porque Santo Tomás a identifica com as regras dos pregadores. ${ }^{6}$

E a vida mesma de Don Juan Manuel é o exemplo de uma vida ativa e não de rejeição e renúncia, é um estar no mundo, viver e lutar nele.

Todos estes princípios serão recolhidos igualmente em $O$ Conde Lucanor: "De três maneiras pode viver o homem: dedicado ao mundo, dedicado ao Céu ou dedicado a um e outro ao mesmo tempo". A primeira maneira é rejeitada, as outras duas são aceitas e, embora considere superior a segunda, afirma: "Nosso Senhor não quer que o mundo seja desamparado dos homens". ${ }^{7}$

Segundo Gimeno Casalduero, a interpretação que faz Don Juan da fórmula dominicana vem dizer o seguinte: "Os votos dos clérigos regulares, como o poder e a riqueza dos príncipes, devem salvar e não condenar os que se submetem a eles".

O Livro dos Estados contém uma exposição doutrinal completa sobre a organização da sociedade que constitui um todo harmônico com a criação e o papel do nobre nesse sistema estamental. Porém, essa doutrina representa mais um ideal, .uma abstração, que uma realidade.

Começa-se a descer à realidade quando essa ordem é quebrada ou pela falta do rei ou do nobre no cumprimento dos seus deveres, ou quando "dever" e "privilégio" deixam de se diferenciar e se voltam um contra o outro. A insistência de Don Juan, tanto na teoria como na prática, pela "guarda das posses, da honra e do estado", nem sempre coincide com a proposta evangélica de salvação da alma.

No contexto histórico da sua época, a primeira percepção que se efetiva é a falta dessa harmonia pressuposta pela organização estamental. A Espanha do século XIV não era um reino, mas basicamente dois reinos cristãos (Castela e Ara-

4

5

6

7

8

Suma Teológica, II sec. I p. Q. 183, . Edição BAC, Madrid, 1955, p. 680.

Libro de los Estados. op. cit. p. 365.

S.T. II,I,q.188 a.2. Madrid, BAC, 1955, p. 825.

El Conde Lucanor. op. cit. p. 439.

GIMENO CASALDUERO,J. op. cit.,. p. 153. 
gão), com dois reis unidos por alianças familiares e posicionamentos concretos, cujo poder e colaboração podiam se contrapor em momentos de crise. ${ }^{9}$ Nada mais contrário ao quadro de harmonia básica que o oferecido pelo ideal dos tratados.

A trajetória política de Don Juan Manuel revela a disparidade entre o ideal político-social que traçam os seus escritos e o caos no qual viveu realmente o seu autor. Os interesses privados do nobre antepunham-se aos interesses do rei e do reino de Castela, não vacilando em fazer alianças com os inimigos do rei, se fosse preciso. As constantes vacilações, ou melhor ainda, as mudanças de vassalagem do Infante falam, sobretudo, da necessidade de aliar-se ao mais poderoso

Entre o nascimento do Infante, como era conhecido, em 1282, e a sua morte em 1348, a sua ação política vincula-se diretamente ao reinado de quatro monarcas em Castela, entremeado por duas regências. Durante esses anos todos, encontra-se no centro da disputa pelo poder e nas intrigas das diferentes facções nobiliárias para conseguir o favor real ou o seu controle que colocaram Castela numa situação de constante anarquia.

Participa em diversas campanhas guerreiras contra os muçulmanos, nas quais a sua atuação nem sempre fica livre de suspeitas, como se manifesta na Crónica de Alfonso XI, atribuindo-lhe uma conduta duvidosa.

Quando, como adelantado ${ }^{10}$ de Murcia, é encarregado das relações entre Aragão e Castela sobre aquele reino, o resultado das negociações traduzem-se na devolução de algumas praças, que não por coincidência estavam sob o senhorio do próprio Infante, e no casamento do mesmo com a filha do rei aragonês, neutralizando assim a ofensiva de Castela e provocando a conseqüente indignação de Fernando IV, que intenta assassiná-lo.

Durante a menoridade de Alfonso XI, volta-se novamente para Castela, para pleitear a tutoria do príncipe, e presta vassalagem a seu rei natural, não sem antes negociar o casamento da sua filha Constança com o rei, seu tutelado. Será o incumprimento deste acordo por parte do rei que o leva novamente a romper com o monarca, desnaturando-se, e declarando-lhe a guerra com o apoio dos reis de Aragão e de Granada.

Novas vacilações na vassalagem, reconciliação e afastamento do seu rei natural, castelhano, presidem os seus últimos anos, buscando sempre o apoio de grupos da nobreza e dos reị de Aragão e Portugal. A definitiva reconciliação com Alfonso XI (1337), representa uma claudicação ou o eclipse político de Don Juan Manuel, que coincide, por outro lado, com a etapa mais fértil da sua produção literária.

Don Juan Manuel reunia na sua pessoa os três elementos fundamentais que, na'Idade Média, caraterizavam o círculo dos "ricos homens" castelhanos: a ascendência, a privança e o patrimônio. Era descendente dos reis de Castela, neto de Fernando III; foi genro de Jaime II de Aragão, tutor de Alfonso XI, cunhado do Arcebispo de Toledo, e apesar do seu declínio político nos últimos anos da sua vida , de neto de rei, após sua morte, passou a ser avô do futuro Juan I de Castela...

9 GIMENEZ SOLER, A. Don Juan Manuel. Biografia y estudio critico. Zaragoza, 1932.

10 Adelantado: autoridade responsável de territórios fronteiriços. 


\section{O Conde Lucanor}

Se toda a produção literária de Don Juan Manuel se orienta para a transmissão da doutrina de uma forma clara e transparente, em O Conde Lucanor, essa característica adquire a máxima expressão através dos exemplos-contos que veiculam a mensagem encarnada na realidade caótica da vida, no qual os comportamentos devem ser interpretados.

A estrutura do livro organiza-se através do diálogo entre duas personagens: 0 Conde Lucanor, que apresenta um problema ou assunto de ordem moral ou política; e o seu conselheiro, Patrônio, que oferece o seu parecer através da narração de um conto ou exemplo.

Cada exemplo, pois, contém uma parte fictícia e outra didática, e está dividido por sua vez em três momentos: o problema ou caso apresentado pelo Conde, o conto-ficção e a sua aplicação ao problema, apresentado pelo conselheiro; e o terceiro, uma máxima que universaliza o valor da resposta, através da intervenção do autor na narrativa e sintetiza, em dois versos, a "moral da história".

Essa estrutura corresponde à primeira parte do livro, à qual se acrescentam outras quatro, contendo uma série de máximas e conselhos sobre os mais variados assuntos e que representam apenas uma quinta parte da obra em seu conjunto.

A escolha do gênero dos exempla tem sido atribuído a uma dupla influência: à ordem dominicana, que a considerava como meio excelente para amenizar a pregação, e à influência árabe, recebida através das versões em castelhano de contos de origem hindu e árabe, tais como Calila e Dimna, Sendebar ou a Disciplina Clericalis, esta última produzida dentro do próprio âmbito cultural do autor. No momento atual a influência árabe tende a ser minimizada. ${ }^{11}$

É o próprio autor quem explica no começo do livro os seus objetivos. "Falarei [...] das coisas que eu entendo que os homens podem aproveitar para a salvação das suas almas e o aproveitamento dos seus corpos e mantimento das suas honras e dos seus estados". Patrônio será o encarregado de frisar que na vida o melhor é guardar "entramas as carreiras", as que são de Deus e do mundo. Uma é inútil sem a outra, sendo que o homem necessita de dois requisitos para seguir qualquer "carreira", "entendimento" e "boas obras", às quais se acrescenta "a fama". ${ }^{12}$

Mas, a preocupação sobre Deus, e ainda sobre o mundo, em Don Juan, afirma Macpherson, fica um pouco abstrata, "limita-se aos seus próprios (problemas), nos quais podem se reconhecer os nobres seus iguais". ${ }^{13}$

Situando-se o Infante, pelo seu nascimento, num estado que o converte em governante e guerreiro, é nesse estado que deve trabalhar constantemente para conseguir os seus fins, os mais concretos dos quais são, precisamente, acrescentar o seu poderio, a sua honra, as suas relações, as suas posses.

11 DEVOTO,D. Textos e contextos: estudio sobre la tradición. Madrid, Gredos, 1974

12 El Conde Lucanor. In op.cit. p. 368.

13 MACPHERSON, I. Los cuentos de un gran señor: la doctrina del Conde Lucanor. In Historia y Crítica de la literatura española: Edad Media. Coord. A.DAYERMOND, Barcelona, Critica, 1979, p. 197 201. 
Quase um terço dos relatos enxiemplos tratam dos conflitos de um governante confrontado com alguém que diz professar-lhe fidelidade ou amizade. $\mathrm{O}$ governante deve aprender a diferenciar e descobrir o que existe por trás de cada manifestação de amizade ou fidelidade, e deve discernir como e quando testar a cada um. Dentro dessa temática o exemplo № $\mathrm{V}$, que oferecemos em anexo, apresenta uma situação arquetípica.

Os diferentes exemplos alertam sobre a mediocridade, a indolência, a autocomplacência, a tolice, a vaidade enganosa ou contra a auto-suficiência. São um convite ao pragmatismo (№ VII do anexo), à discrição criteriosa, e sempre uma prova de sagacidade e cautela.

A título de exemplo selecionamos três contos que resumimos, seguindo a estrutura interna a que aludíamos anteriormente.

I - EXEMPLO № V: Do que aconteceu a um paposo com um corvo que levava um bocado de queijo no bico.

1- O conde Lucanor expõe o seu problema a Patrônio:

Um homem, que se diz seu amigo, começou a louvá-lo muito e deu-lhe a entender as muitas qualidades que havia nele, de honra, poder e bondade. Depois de toda essa bajulação, fez uma proposta de negócios que o conde considerava conveniente para ele. Exposto o negócio, pede conselho.

2- Patrônio alerta o conde sobre o possível engano e narra o conto:

A - Um corvo encontrou um bocado de queijo e subiu numa árvore para comê-lo sem ser perturbado. Porém um raposo, que estava embaixo, o viu e começou a cogitar como tirar-lhe o queijo. Então, dirigiu-se ao corvo louvando a sua nobreza, galhardia, fama, agilidade, fortaleza e beleza, sem deixar de ressaltar as criticas que outros faziam dessas mesmas qualidades como prova de imparcialidade. E termina dizendo-lhe: "já que Deus faz todas as coisas com razão...não consentiria que ...ele tivesse a falha de não cantar melhor que as outras aves, ... se eu pudesse ouvir o vosso canto, considerar-me-ia afortunado para sempre". O corvo acreditando no raposo e tomando-o como amigo, abriu o bico para cantar, o queijo caiu no chão e o raposo tomando-o foi embora.

B - Explicação de Patrônio pontualizando a interpretação da história. "Entenda - diz o conselheiro - que apesar de ser a intenção do raposo enganar o corvo, as suas razões sempre foram com verdade. $E$ tenha por certo que os danos mortais sempre são os que se dizem com verdade enganosa". "Assim foi enganado o corvo pelo raposo acreditando que havia em si mesmo mais apostura e perfeição do que era certo".

- E vós, senhor conde Lucanor...perceba que aquele homem, bajulandovos e louvando-vos além da realidade, "entenda que o faz para enganarvos".

3- Máxima: Quien te alaba por lo que no hay en ti. sabe que quiere llevarse lo que hay en ti. 
II - EXEMPLO № VI: Do que aconteceu a um homem com a andorinha e o pardal.

1 - O conde expõe o seu problema:

Já que não pode evitar o choque com um dos seus vizinhos, que deve fazer, sendo que o mais próximo não é tão poderoso como o mais afastado.

2 - Patrônio narra o conto:

A - Um homem não podia dormir pelo barulho que faziam as andorinhas e pardais na sua casa e pede auxilio a um amigo para desfazer-se das aves; este lhe oferece um feitiço que somente serviria contra uns. O que fazer, de qual desembaraçar-se. As andorinhas provocam maior escândalo, porém "vão e vem". Os pardais fazem menos barulho, porém "sempre estão em casa".

B - E vós, senhor conde...

"Embora aquele que vive mais longe seja mais poderoso, aconselho-vos ter contenda com aquele que está mais perto, embora não seja tão poderoso".

3 - Máxima: Si de todas formas contienda has de tener soporta la de mas lejos, aunque tenga mas poder

III - EXEMPLO № XVII: Do que aconteceu a um homem que tinha muita fome e ao qual, de má vontade, convidaram outros a comer.

1 - O conde expõe o seu problema:

Um homem se aproxima do conde e lhe faz uma proposta, "frouxamente" dando a entender que preferia que não aceitasse. Por outro lado, essa proposta era conveniente ao conde, o qual receia aceitá-la, pelas condições em que tinha sido feita.

2 - Patrônio narra o conto:

A - Um homem que tinha sido rico estava na miséria, passando fome, mas tinha vergonha de pedir. Um dia passou pela casa de um conhecido na hora de comer, e este, "de má vontade", por cortesia, lhe perguntou se queria comer com ele. $\mathrm{O}$ homem aceita o convite dizendo "já que tanto me insiste para comer convosco, não me parece apropriado contradizer a vossa vontade". E ...matou a fome.

B - E vós, senhor conde...

Se entenderdes que aquilo que se lhe propõe é proveitoso para vós, não espereis que insistam, porque podem voltar atrás. Fazei entender que aceitais a proposta porque o outro a ofereceu, pois seria mais vergonhoso solicitar vós o que ele oferece.

3 - Máxima: En lo que tu provecho pudieres hallar nunca te hagas mucho de rogar

Por outro lado, ao longo dos diferentes exemplos, aparecem indícios claros da consciência que o Infante tem da dificuldade de conciliar os dois caminhos propostos para o homem, buscando mais uma vez o argumento tomista do amor a si mes- 
mo. Um homem tem que ser o que é, o que Deus quer dele. Se no mundo nasceu em estado de nobre e de guerreiro, o dever para si mesmo, para os que dependem dele, para os seus iguais e para Deus, é ser um bom nobre e guerreiro.

Em O Conde Lucanor, oferecem-se exemplos para ser todas essas coisas. Os contos narrados e a moral da história que os acompanha são uma genial tentativa de conciliação e até certo modo de dourar a pilula.

Os exemplos que apresentamos não necessitam de muitas interpretações, o que aliás já se faz na própria obra; estão aí com uma força, a das imagens criadas, que ultrapassa a eficácia da teoria sistemática dos tratados filosóficos, para aterrizar na prática de uma política realista e cotidiana, que nem por isso ignora o conhecimento da natureza humana. 